\title{
Denture Adhesives - A Literature Review
}

\author{
Sudhanshu Shekar ${ }^{*}$, Sanjeev Mittal and Nikhil Kalra
}

Department of Prosthodontics, Maharishi Markandeshwar University, Ambala, Haryana, India

*Corresponding author: Dr. Sudhanshu Shekar, Department of Prosthodontics, Maharishi Markandeshwar University, Ambala, Haryana, India, Tel: +91 9056442233; Email: sshekhar62@gmail.com

Rec date: Jan 17, 2016; Acc date: Feb 23, 2016; Pub date: Feb 29, 2016

Copyright: ( 2016 Shekar S, et al. This is an open-access article distributed under the terms of the Creative Commons Attribution License, which permits unrestricted use, distribution, and reproduction in any medium, provided the original author and source are credited.

\begin{abstract}
Successful complete denture treatment combines exemplary technique, effective patient rapport and education and familiarity with all possible management options to provide the highest degree of patient satisfaction. Dentists need to know about denture adhesives to be able to identify those patients who actually need them and to be able to educate them about the advantages, disadvantages and correct use of these products. Denture adhesives are commercially available nontoxic, soluble materials that when applied to the tissue surface of dentures enhance their retention, stability and performance. They were introduced in dentistry in the late 18th century. The first patent related to adhesives was issued in 1913, followed in the 1920s and 1930s. The purpose of the use of denture adhesives can be described as to subjectively benefit denture-wearers with improved stability, retention and comfort of their dentures, and with improved incisal force, masticatory ability, and confidence.
\end{abstract}

Keywords: Dentures; Denture adhesives; Dental implants; Prosthesis

\section{Introduction}

A comfortable and durable denture is every patient's right and desire. A successful and complete denture treatment however combines a good technique, effective patient rapport and patient familiarity with the possible management options so as to provide maximum satisfaction to the patient. All these are possible if certain fundamentals about stress distribution and tissue preservation are well balanced. As evidenced and stated by Hardy and Kapur retention of a complete denture may be influenced by a number of factors like physical, physiological, psychological, mechanical and surgical [1].

There are some forcing situations where providing desirable retention to the denture may be a problem. Dental experts and professionals have taken years to identify that denture adhesives are pivotal as a means to enhance denture retention, stability and function [2]. The major reason that holds back professionals from using these is that they feel adhesive usage as a poor reflection of their clinical skills and prosthetic expertise [3]. Usually during the process of impression taking, it is made sure by the dentist that there is maximum area of coverage for maximum tissue-denture contact, and then an effective border seal. But in some situations, the use of denture retention materials/techniques, like implants and denture adhesives becomes indispensible [3]. This might be in cases such as immediate restorations, complicated prostheses-obturators, dry mouth, the difficult and demanding patient, poor ridge anatomy and relations, and in public like attorneys, actors, and politicians. Also, with the passage of time, shrinkage in the bone structure in the mouth causes dentures to gradually become loose. In such cases, the dentures should be realigned or new dentures must be made that fit the mouth properly. Denture adhesives fill gaps caused by shrinking bone and give temporary relief from the loosening dentures. Jagger et al. have outlined some more situations where the use of denture adhesives becomes mandatory for the improvement of the quality of retention [4]. These are cases of severely atrophied edentulous ridges of severe grade; severely abused/hypertrophied tissue covering the ridges; patients having lack of neuromuscular control (e.g. stroke and Parkinsonism); cases with xerostomia; maxillofacial defects which provides inadequate tissue support and patients with lack of neuromuscular control.

The Glossary of Prosthodontic terms defines denture retention as "the resistance of a denture to dislodgement" [5]. As defined by the United States Food and Drug Administration (US-FDA), 'Denture adhesives are pastes, powders or adhesive pads that may be placed in/on dentures to help them stay in place. Sometimes denture adhesives contain zinc to enhance adhesion' [6]. In other words, denture adhesives are commercially available nontoxic, soluble materials that when applied to the tissue surface of dentures enhance their retention, stability and performance [7].

\section{Mechanism of Action}

Way back in 1991, Shay had described the mechanism of action of most of these denture adhesives [8]. He studied that these materials swell from $50-150 \%$ by volume in the presence of water, filling the spaces between the prosthesis and the tissues. They enhance the interfacial forces by increasing the adhesive and cohesive properties and viscosity of the medium lying between the denture and the basal seat and eliminating the voids between the denture base and the basal seat [8].

\section{What does literature say?}

Majorly there are two types of denture adhesives available for use, soluble, like carboxymethylcellulose (CMC), calcium and zinc salts, etc. and insoluble, like pads and synthetic resins, groups [9]. There is ample literature available as guidelines on the rational use of dental adhesives and the related contradictions. Tella et al. have listed points as to when these dentures are actually indicated and when not. Before using these denture adhesives, it needs to be assessed as per the need of the patient that which denture adhesive is best suitable. But, at all times 
Page 2 of 2

it must be remembered that in cases of ill-fitting dentures, they might not be the solution [10].

Among the vast materials available that act as denture adhesives, professionals have been facing dilemmas as to which one of these materials available are most effective and can play a good role in enhancing the longevity of any denture. Dentists have been studying the adhesive strengths of these materials, comparing them to each other, so as to come out with a single agent proven best. Ozcan et al. and Psillakis et al. have recently reported significant benefit of using denture adhesives in improving the retention and stability of the tested prosthesis $[10,11]$.

\section{Discussion}

Several studies have been conducted from time to time to study the efficacy of denture adhesives. With using a well-fitting denture the result become more precise in expression of the effectiveness of denture adhesive that is used according its indication by denture wearers. Mechanical interference, such as undercuts usually present in clinical situation would contribute further resistance to dislodgment in addition to vertical retention forces. So the dislodgment of well-fitting denture in the presence of severe undercut required high force that might cause possible damage to the tissue or cause pain and discomfort to the patients. Denture adhesives may be helpful in such cases also. In an ideal situation, an edentulous patient will have prominent alveolar ridges and a repeatable centric relation, in such a case denture adhesive may not be needed. But, as the patient ages, and is affected by chronic illness, and has a limited access to complete oral health care, denture adhesives can be an effective part of denture care and aftercare.

\section{References}

1. Hardy IR, Kapur KK (1958) Posterior border seal-its rational and importance. J Prosthet Dent 8: 386-397.

2. Chowdhry P, Phukela SS, Patil R, Yadav H (2010) A study to evaluate the retentive ability of different denture adhesive materials: an in vitro study. J Indian Prosthodont Soc 10: 176-181.

3. Grasso JE, Rendell J, Gay T (1994) Effect of denture adhesive on the retention and stability of maxillary dentures. J Prosthet Dent 72: 399-405.

4. Jagger DC, Harrison A (1996) Denture fixatives-an update for general dental practice. Br Dent J 180: 311-313.

5. The Academy of Prosthodontics (2005) Glossary of Prosthodontic Terms (8th edn), Mosby, St. Louis.

6. U.S. Food and Drug Administration.

7. Musani S, Dugal R, Kothavade M (2010) A review of denture adhesives used in the dental profession. Annals and Essences of Dentistry 3: 129-133.

8. Shay K (1991) Denture adhesives. Choosing the right powders and pastes. J Am Dent Assoc 122: 70-76.

9. Tella S, Kumar TK, Radhakrishnan M (2013) Denture Adhesives. Indian J Dent Adv 5: 1323-1325.

10. Ozcan M, Kulak Y, de Baat C, Arikan A, Ucankale M. The effect of a new denture adhesive on bite force until denture dislodgement. J Prosthodont 14: $122-126$

11. Psillakis JJ, Wright RF, Grbic JT, Lamster IB (2004) In practice evaluation of a denture adhesive using a gnathometer. J Prosthodont 13: 244-250. 